\title{
PROBLEMÁTICA SOCIOAMBIENTAL URBANA
}

\author{
Urban socioenvironmental problematic \\ La problématique socioenvironnementale urbaine
}

\section{Francisco Mendonça}

Doutorado em Ciências - Geografia Física. Docente no Programa de Pós-graduação da Universidade Federal do Paraná. Rua Fernandes de Barros, 1732 /05 Hugo Lange 80040-450 Curitiba PR. E-mail para contato: chico@ufpr.br

\section{Fabio Cesar Alves Cunha}

Doutorado Geografia Humana, Unesp Pres. Prudente 2005; Pós-doutorado: Universidade Federal do Paraná - UFPR 2013. Universidade Estadual de Londrina UEL - Docente do Programa de Pósgraduação em Geografia. Rua Benjamin Franklin, 220, casa 5. Londrina PR, cep. 86.063-240. E-mail: fabioalvescunha@gmail.com

\section{Gislaine Cristina Luiz}

Doutorado em Geotecnia Ambiental pela Universidade de Brasília. Docente no Programa de Pósgraduação em Geografia da Universidade Federal de Goiás (UFG). Universidade Federal de Goiás, Instituto de Estudos Socioambientais. Av. Esperança, s/n, Campus Samambaia, 74.690-900, GoiâniaGO.E-mail:gislaineluiz@yahoo.com.br

\section{RESUMO}

A ANPEGE - Associação Nacional de pós-graduação e Pesquisa em Geografia - foi criada nos anos 1990 no contexto da redemocratização do Brasil. Para dinamizar a produção do conhecimento embasada no debate de ideias ela organiza o ENANPEGE - Encontro Nacional da ANPEGE - a cada dois anos. Os GTs - Grupos de Trabalho - constituem atividades de apresentação e debate da produção de conhecimentos da pós-graduação em geografia no Brasil. O GT - Problemática Socioambiental Urbana foi criado em 2009 e aglutina professores, pesquisadores e estudantes em torno da abordagem dos problemas derivados da interação sociedade-natureza nas cidades. Ele envolve, portanto, perspectivas integradas da geografia física e da geografia humana no tratamento de problemas socioambientais urbanos, tais como situações de risco e de vulnerabilidade socioambiental, resíduos sólidos, questão hídrica, conforto ambiental e qualidade do ar, áreas verdes urbanas, favelização e condições de vida,entre outros. 51 contribuições científicas proveniente de todo o Brasil foram aprovadas para o XI ENANPEGE realizado em 2015 na cidade de Presidente Prudente / SP, sendo que 27 delas foram apresentadas e debatidas no evento.

Palavras-chave: Ambiente urbano, problemas socioambientais, geografia, Brasil. 


\begin{abstract}
The ANPEGE - National Association of Graduate Studies and Research in Geography was created in the 1990s in the context of re-democratization of Brazil. To stimulate the production of knowledge based in the debate of ideas its organizes the ENANPEGE National Meeting of ANPEGE - every two years. The GTs - Working Groups - constitute an activity to promote the debate concerning graduate production of knowledge in geography in Brazil. The GT -Urban SocioenvironmentalProblematic was created in 2009 and brings together teachers, researchers and students around the approach to the problems arising from the interaction between society and nature in cities. It involves, therefore, integrated perspective of physical geography and human geography in the treatment of urban environmental problems such as risk situations and environmental vulnerability, solid waste, water issue, environmental comfort and air quality, urban green areas, slums and living conditions, etc. 51 scientific contributions from all over Brazil have been approved for the XI ENANPEGE, and 27 of them were presented and discussed at the event.
\end{abstract}

Keywords: Urban environment, socioenvironmental problems, geography, Brazil.

\title{
RESUMEN
}

La ANPEGE -AsociaciónNacional de Pos-graduaciónyInvestigación en Geografíafuecreada en la década de 1990 en el contexto de la redemocratización de Brasil. Para estimular la producción de conocimientoenraizado en el debate de las ideas la association organiza el ENANPEGE -EncuentroNacionalde la ANPEGE - cada dos años. Los GTs Grupos de Trabajo-promovenactividades y debates de la producción de conocimientos en geografía en la pos-graduación en Brasil. El GT -ProblemasAmbientalesUrbanas se creó en 2009 y reúne a professores, investigadores y estudiantes de todo elpaís conenfoque de los problemasquesurgen de la interacción entre la sociedad y la naturaleza en lasciudades. Se trata, por lo tanto, la perspective integrada de la geografíafísica y la geografíahumana en el tratamiento de los problemasambientalesurbanos, tales comosituaciones de riesgo y vulnerabilidadambiental, residues sólidos, tema del agua, el confortambiental y calidad del aire, zonasverdesurbanas, y condiciones de vidaen barrios pobres, etc., entre otros. 51 contribucionescientíficas de todoBrasilhansidoaprobadosparael XI ENANPEGE celebrado en 2015 en la ciudad de PresidentePrudente / SP, y 27 de ellosfueronpresentados y discutidos en el evento.

Palabras-clave: Ambienteurbano, problemassocioambientales, geografia, Brasil. 


\section{INTRODUÇÃO}

Um pujanteprocesso de criação de cursos strictu sensu marcou a história da ciência acadêmica no Brasil a partir das últimas décadas do século XX, sendo que praticamente todo o território nacional registrou a formação de cursos variados de mestrado e de doutorado. Para além do atendimento aos critérios oficiais de qualidade, balizados em cursos congêneres de países desenvolvidos, os diferentes campos disciplinares e interdisciplinares buscaram atingir outras perspectivas que não somente aquelas de ordem institucional. Assim, e também como uma marca da redemocratização brasileira, as décadas de 1980 e 1990 atestaram a criação de um numero considerável de instituições de defesa e promoção da produção cientifica no país.

O debate de ideias constitui um dos principais elementos para o avanço e o aprofundamento da produção do conhecimento científico e intelectual. De um formato bastante diretivo e escolástico, que predominou até meados dos anos 1980, a formação em nível de mestrado e doutorado no Brasil registra um considerável salto, qualitativo e quantitativo, nas últimas décadas, em todos os campos do conhecimento. Estratégias de ensino-aprendizagem embasadas na construção coletiva e conjuntiva do conhecimento tem ganhado cada vez mais destaque, sobressaindo-se experiências coletivas e interativas, cujos processos de feedback mais acelerados nestes tempos tecnologizados, parecem apresentar uma velocidade mais rápida que outrora... acelerando, portanto, a produção do conhecimento científico.

Neste contexto nasceu a ANPEGE - Associação Nacional de Pesquisa e Pós-graduação em Geografia -entidade que tem se dedicado à promoção e fortalecimento da ciência geográfica no Brasil. Inaugurada com o propósito de aprofundar o conhecimento deste campo do conhecimento através do intercambio e debates de ideias, a ANPEGE tem atuado na promoção do conhecimento geográfico através de diversas atividades. Para além das conferencias, palestras e publicações a entidade construiu, já na primeira década de funcionamento, os espaços de apresentação e discussão da produção cientifica dos diferentes programas do país, nominadosGTs - Grupos de Trabalho.

No âmbito dos GTs, cujas temáticas são propostas por pesquisadores vinculados aos programas de pós-graduação em geografia brasileiros, interagem tanto professores quanto pesquisadores e estudantes de mestrado e de doutorado. A dinâmica de cada GT é bastante variada, mas todos realizam suas atividades tendo como organização a seleção prévia das contribuições científicas voluntariamente inscritas nos mesmos. A atividade constitui um momento importante para o aprofundamento de opções teórico-conceituais, metodológicas e mesmo de estudos de caso dos participantes, além de evidenciar o estado 
da arte das diferentes temáticas em curso nos programas, bem como pontuar seus avanços e desafios. Trata-se de uma reunião instigadora ao avanço do conhecimento, ao mesmo tempo em que constituem uma excelente oportunidade para a troca de ideias no âmbito da pós-graduação brasileira.

A abordagem geográfica das cidades, ou do fato urbano, foi elaborada historicamente privilegiando analises embasadas na perspectiva da construção humana-social deste objeto de estudo. Tomaram relevo neste subramo da geografia - geografia urbana - os estudos relacionados à urbanização, movimentos sociais, mobilidade humana, habitação, industrialização, urbanismo, segregação espacial, justiça social, dentre vários outros, todos tratados desde a perspectiva da organização humana sobre o espaço e/ou de sua produção. A história da geografia urbana é rica em interessantes e qualificadas produções, especialmente no Brasil, cuja intensa urbanização após 1970 desencadeou uma expressiva quantidade de estudos chegando a constituir esta subárea num dos maiores GTs da ANPEGE.

Inúmeros problemas derivados da interação entre a sociedade e a natureza nas cidades, especialmente enfocadas no contexto do desenvolvimento da abordagem ambiental na geografia, tomaram relevo após a década de 1960, momento no qual a população urbana ultrapassou a população rural no Brasil. A intensa e desordenada urbanização do país, com a consequente degradação social e ambiental registrada nas cidades (Monteiro, 1976; Santos, 1993), resultou na formação de ambientes e situações de vida marcadas por elevada complexidadee, consequentemente, o surgimento de grupos preocupados com estudos sobre o "ambiente urbano" (Mendonça, 2004).

O ambiente urbano como tema de estudo da geografia tem como preocupações principais os problemas derivados da alteração a natureza pelo homem no âmbito das cidades, assim como das repercussões desta alteração sobre as condições de vida dos citadinos. Várias perspectivas de compreensão desta complexa interação - sociedade e natureza - tem sido lançadas nas últimas décadas; todavia, para fins de compreensão da concepção norteadora dos debates travados no âmbito do GT - Problemática Socioambiental Urbana - retoma-se aqui a contribuição do PNUD (figura 1) lançada em 1997. Conforme os pesquisadores desta renomada instituição a problemática ambiental urbana resulta da interação entre os três subsistemas que formam o ambiente urbano, quais sejam: $\mathrm{O}$ subsistema natural, o subsistema construído, e o subsistema humano/social; as dinâmicas a eles associadas revelam precariedade, esgotamento, deterioração e contaminação, posto que são marcadas por pressões sociais que incrementam a opulência e aumenta a pobreza, donde compreender tais problemas como intrinsecamente associados aos processos de produção e reprodução do espaço urbano, especialmente em países não desenvolvidos. 
Fig. 1 - Dinâmica da problemática ambiental

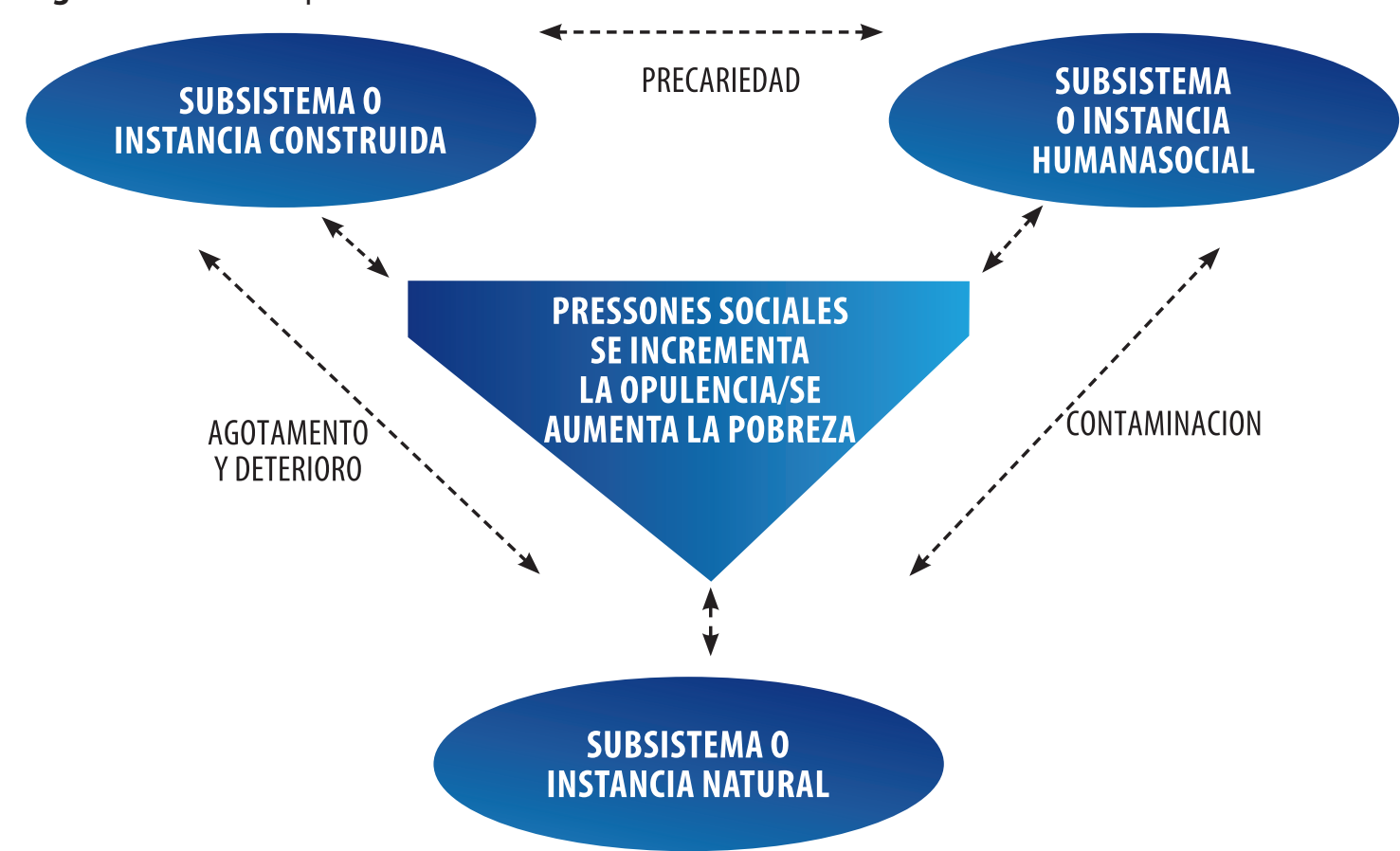

Fonte: PNDU/UNOPS, $1997(p g .65)$

Várias contribuições científicas enfocando tais problemáticas eram encaminhadas ao GT de Geografia Urbana da ANPEGE nos seus primórdios; este grupo cresceu muito rapidamente, o que suscitou a criação do GT-Problemática Ambiental Urbana, dado não somente ao volume de trabalhos vinculados à abordagem da interação entre a sociedade e natureza na cidade, mas principalmente devido à matrizes teórico-metodológicas distantes do núcleo de trabalhos da abordagem clássica da geografia urbana em si mesma.

Tanto na geografia brasileira quanto em muitos outros campos do conhecimento entende-se, na atualidade, que a crise ambiental contemporânea não pode ser compreendida nem resolvida segundo perspectivas que isolem a sociedade da natureza, ou que ignorem uma delas. Para Moscovici (2007, p. 32) é o momento em que é preciso "restabelecer a unidade quebrada ou perdida entre duas partes de nossa existência, de nossa vida, a sociedade e a natureza, como se elas fossem anteriores à fratura operada pelo movimento histórico". Nesse contexto surgem formas de expressar a perspectiva da inter-relação entre homem/sociedade e natureza/ambiente, destacando o surgimento, uso e difusão do termo socioambiental tanto na ciência em geral quanto no particular da geografia (MENDONÇA, 2001; VEIGA, 2007). 
Otermosocioambiental passou a ser amplamente utilizado pelas diversas ciências a partir do final doséculo XX, tendo também sido registrado no âmbito da geografia brasileira. Nos últimos anos uma série de trabalhos e pesquisas na área faz uso deste discurso, culminado com a proposta da formação de uma Geografia Socioambiental no país (MENDONÇA, 2001). Para verificar esta construção analisou-se, junto à produção cientifica brasileira derivada da pós-graduação, especialmente teses de doutorado (2264 até o ano de 2014, das quais 324 registraram o emprego do termo e somente $48 \mathrm{com}$ argumentação sobre o mesmo), os argumentos elaborados nos discursos da abordagem socioambiental geográfica no país (PINTO, 2015).

Tendo por base a análise de discurso (FOUCAULT, 2013) aplicada sobre o conjunto de teses apreciadas constatou-se que há um crescimento do número de teses após o ano 2000 que desenvolvem o discurso socioambiental no âmbito da geografia brasileira, e que elas são produzidas nos diferentes programas de pós-graduação em geografia no país, por diferentes professores-orientadores. Constata-se, assim, que a abordagem socioambiental constitui-se numa importante e destacada tendência nos estudos da relação sociedadenatureza no campo geográfico da ciência brasileira, especialmente no contexto das cidades.

Para o evento realizado em Presidente Prudente, em outubro de 2015, o GT recebeu cerca setenta propostas, das quais 43 contribuições foram aprovadas para apresentação na forma oral, e 08 na forma de pôster, somando 51 contribuições científicas; do total de trabalhos aprovados apenas cerca de 50\% foram apresentados e debatidos durante a realização do evento. Os trabalhos foram agrupados em 5subeixos, que são: a)Riscos e vulnerabilidades socioambientais urbanos; b) Recursos hídricos nas cidades; c) Resíduos sólidos urbanos;d) Proteção e preservação ambiental urbana e, e) Outros temas.

\section{RISCOS E VULNERABILIDADES.}

Os problemas socioambientais urbanos podem ser compreendidos e analisados sob diferentes perspectivas. Em boa parte das vezes, e devido principalmente à complexidade dos mesmos, torna-se necessário utilizar o recurso do ecletismo metodológico para desenvolver estudos e analises que o contemplem de maneira ampla e satisfatória. Mas não se trata de um ecletismo qualquer, como bem o apontou Mendonça (2004); cada problema enfocado demanda uma perspectiva particular para sua interpretação, sendo sua especificidade que irá realçar os caminhos da interpretação a ser desenvolvida. Assim é que a queda da qualidade da água urbana, por exemplo, irá demandar a compreensão de sua condição hidrográfica e hidrológica, assim como sua composição físico-química, as formas de sua apropriação e degradação, os contextos político-culturais dos processos 
que culminam no seu comprometimento que irá, em última instância, incidir sobre a qualidade de vida da população. Num tal contexto há que se fazer recurso de métodos de interpretação e investigação tanto das ciências naturais quanto das ciências humanas e sociais; o exercício é necessário ainda que os riscos de alguma superficialidade e de maior ênfase numa ou noutra parte do estudo.

Visando contribuir com a construção teórica e metodológica dos estudos do ambiente urbano Mendonça (2004), embasando-se em variadas proposições analíticas sobre o tema, construiu o S.A.U. - Sistema Ambiental Urbano (Figura 2) - cujo emprego tem sido bastante significativo na geografia na última década. A construção inicial visou orientar estudos na compreensão do ambiente urbano como um sistema complexo derivado da interação entre a natureza, a sociedade e os elementos dinamizadores desta interação na cidade, estando estes na gênese dos problemas socioambientais variados dos contextos urbanos. Em etapa mais recente o autor inseriu na sua construção a perspectiva de também enfocar o S.A.U. considerandoos riscos e vulnerabilidades socioambientais, posto que estas duas condições tem ganhado cada vez maior importância na atualidade devido à intensificação dos impactos dos eventos extremos (naturais, sociais e tecnológicos) sobre a sociedade, especialmente sobre as sociedades urbanas.

Fig. 2 - S.A.U. - Sistema Socioambiental Urbano

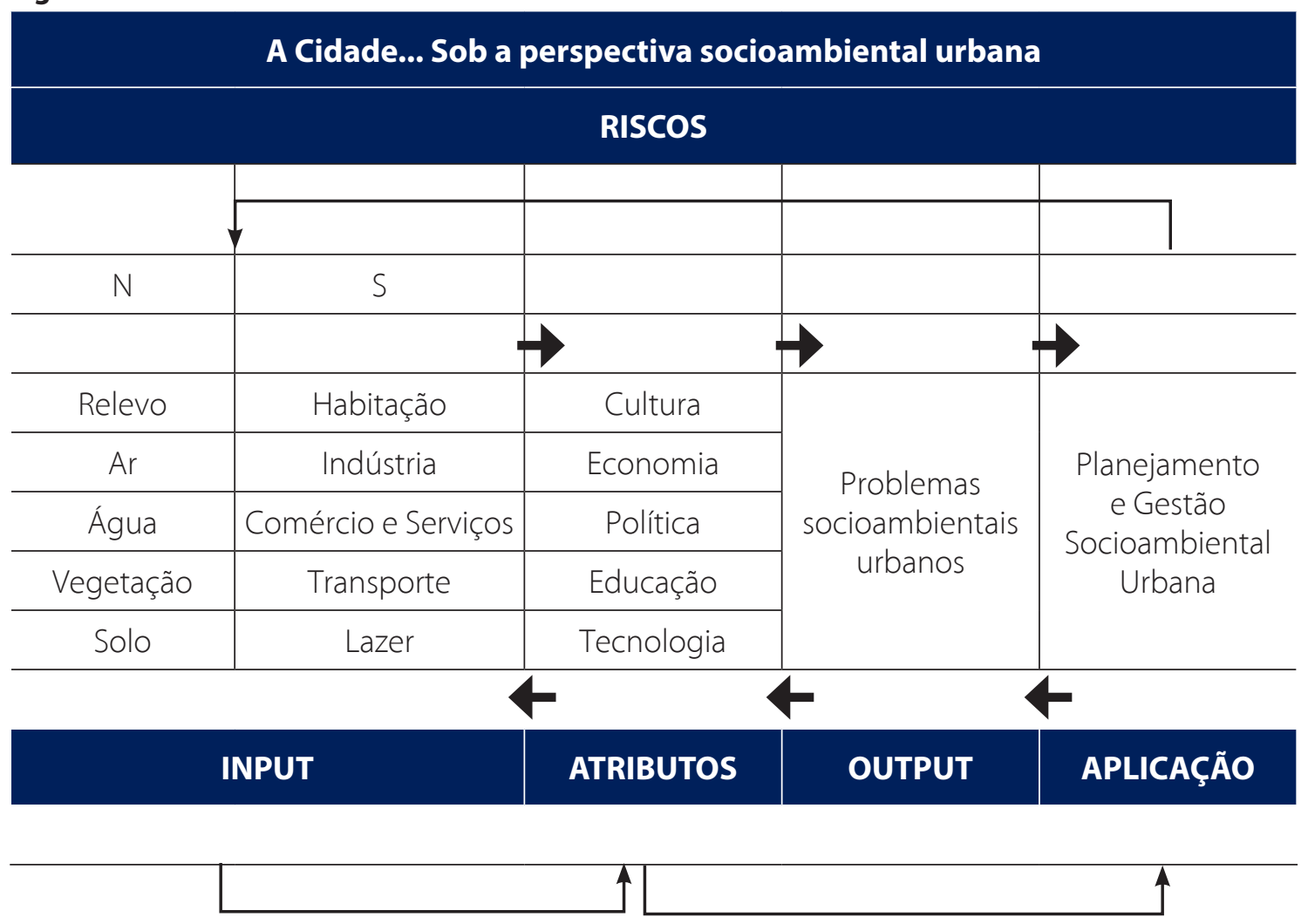


O tema risco e vulnerabilidade vem recebendo atenção crescente nos últimos anos, como pode ser visto nos trabalhos de Beck(1992), Veyret(2003), Mendonça (2004), Deschamps (2004), Marandola e Hogan (2004), dentre outros. O crescimento acelerado e contínuo, principalmente, das médias e grandes cidades, associado à falta ou insuficiência de planejamento e intensa especulação imobiliária, faz com que esses locais estejam cada vez mais propícios a riscos de várias naturezas, que acarretam vulnerabilidades diferenciadas. Risco e vulnerabilidade ainda são agravados pela maior incidência e intensidade de eventos naturais extremos como tempestades acompanhadas de elevada precipitação pluviométrica, enchentes e deslizamentos, que causam vítimas e prejuízos materiais considerados, sobretudo, em áreas mais ocupadas. Este cenário faz do meio urbano um lócus distinto de risco e vulnerabilidade na sociedade moderna. Assim, este tema vem se mostrando muito presente no estudo da problemática socioambiental urbana.

Veyret (2007, p.11) considera o risco um objeto social definido como a percepção de um determinado perigo por um indivíduo ou grupo social. Não há risco sem uma população ou indivíduo que o perceba e que poderia sofrer seus efeitos. O risco é a tradução de uma ameaça. Segundo ela (2007, p. 63), existem inúmeros riscos e as abordagens variadas podem conduzir a diferentes tipologias.

Assim, uma das categorias mais frequentemente evocadas concerne aos riscos naturais, eles próprios classificados no grupo dos riscos ambientais. As políticas econômicas podem gerar riscos econômicos e financeiros. As decisões políticas estão na origem dos riscos geopolíticos, os quais se exprimem em escalas muito variadas. As migrações, o crescimento urbano, fazem nascer riscos sociais: insegurança, violência urbana. [...] Os diferentes fatores de risco evocados interagem uns com os outros, de modo que alguns riscos pertencem simultaneamente a diversas categorias (VEYRET, 2007, p. 63).

A autora ainda considera três grandes conjuntos de riscos: os riscos ambientais, os riscos industriais-tecnológicos e os riscos econômicos, geopolíticos e sociais. Um destes tipos de risco raramente acontece de forma isolada, sobretudo porque explicita a condição de determinados impactos sobre a sociedade, sendo que na maioria das vezes constituemse em riscos híbridos; tendo um elemento desencadeador na natureza, o risco natural por exemplo, ele se intensifica e se repercute sobre uma dada sociedade, o que o torna um fenômeno complexo e múltiplo, donde concebê-lo como risco hibrido.

Com base nessa tipologia, é possível constatar que um determinado risco pode deflagrar outros riscos. A potencialidade de um deslizamento em áreas urbanas com alta declividade é um risco ambiental que gera, consequentemente, um risco social à medida que populações urbanas estejam envolvidas nessas áreas. Este é um outro exemplo que evidencia a concepção de "riscos híbridos", especialmente quando se considera que os riscos constituem um construto social. 
A vulnerabilidade pode ser entendida enquanto condição de uma determinada população que está sujeita, vulnerável, sensível a determinadas situações de riscos.

Para Esteves(2011, p. 69)

[...] a vulnerabilidade envolve um conjunto de fatores que pode diminuir ou aumentar $\mathrm{o}(\mathrm{s})$ risco(s) ao qual o ser humano, individualmente ou em grupo, está exposto nas diversas situações da sua vida. Essas situações podem ser, por exemplo, uma enchente, um deslizamento, a perda de um emprego, uma despesa não esperada, uma doença, a marginalização social, uma recessão econômica, entre outras.

Uma tal concepção conduz à adjetivação da vulnerabilidade em termos ou esferas específicas, tais como vulnerabilidade social, política, econômica, ambiental, cultural, habitacional, etc. A vulnerabilidade social é amplamente utilizada no campo das ciências sociais para embasar políticas públicas voltadas aos setores mais vulneráveis da sociedade, e pode ser concebida como

[...] uma situação em que os recursos e habilidades de um dado grupo social são insuficientes e inadequados para lidar com as oportunidades oferecidas pela sociedade. Essas oportunidades constituem uma forma de ascender a maiores níveis de bem-estar ou diminuir probabilidades de deterioração das condições de vida de determinados atores sociais(ABRAMOVAY et al.,2002, p.30).

$\mathrm{Na}$ Geografia, a vulnerabilidade se apresenta de forma mais clara em três contextos, o social, o tecnológico e o ambiental, e vem incorporando ao debate a dimensão espacial.

Esta abordagem parte das dinâmicas que configuram uma dada espacialidade, procurando circunscrever sua escala (uma região, uma cidade, um ecossistema, um bairro), identificando nas interações entre sociedade e natureza os riscos e perigos que atingem o lugar. Não se trata de entender esta espacialidade enquanto substrato físico independente da sociedade. Antes, a abordagem busca uma unidade de referência para compreender o contexto da produção social do perigo em conexão com o contexto geográfico na delimitação da escala espacial. O resultado desta relação, suas tensões, aberturas, estruturas de proteção e risco, permite identificar a vulnerabilidade (MARANDOLA JR.; HOGAN, 2006, p.36).

A dimensão temporal também deve ser levada em consideração ao se abordar esta subtemática da problemáticasocioambiental urbana, pois os riscos e, consequentemente, as vulnerabilidades podem estar associados a: a) determinados fenômenos que configuram sazonalidades diferenciadas, como é o caso de enchentes e deslizamentos relacionados aos meses mais chuvosos no ano, ainda que algumas excepcionalidades fujam à regra; $\mathrm{e}$, b) ocorrem distintamente no âmbito dos espaços urbanos, ou seja, os impactos dos riscos explicitam condições altamente diferenciadas da produção do espaço urbano, posto que decorrem de situações de vulnerabilidade socioambiental distintas dos tecidos urbanos. 
Segundo Esteves (2011 p.75), além da vulnerabilidade social existe uma tendência para estudos que envolvem situações classificadas como vulnerabilidade ambiental, que representa o grau de suscetibilidade natural de um ambiente ou a vulnerabilidade socioambiental, quando esta suscetibilidade é fruto da relação entre o ambiente físiconatural e a ação da sociedade sobre o mesmo.

Segundo ele:

ao integrar as dimensões sociais e ambientais na identificação e análise da vulnerabilidade, é pertinente a adoção da terminologia vulnerabilidade socioambiental. Essa premissa se justifica porque a vulnerabilidade aos riscos ambientais depende de fatores sociais, econômicos, tecnológicos, culturais, ambientais e a relação destes com o ambiente físiconatural, envolvendo, portanto, adinâmica social e a dinâmica ambiental, esta última, inclusive, quando em estado de degradação.

Assim, pode-se falar em vulnerabilidade socioambiental mas, também, em risco socioambiental, quando as causas de um determinado risco ou perigo não são naturais, mas derivadas da associação de fatores naturais do meio físico com a dinâmica da sociedade envolvida. Uma encosta da mata atlântica não ocupada pode sofrer deslizamentos em eventos de alta precipitação pluviométrica, como ocorreu em algumas encostas do município de Angra dos Reis no ano de 2010; neste caso, pode-se falar em risco ambiental. Diferentemente, no caso de deslizamentos que ocorrem e que também ocorreram naquele município devido a uma instabilidade da encosta provocada ou agravada por ocupações irregulares de habitações humanas, geralmente as classes mais pobres. Neste segundo caso não se tem um risco ambiental, mas socioambiental.

Apesar de estarem associados, risco e vulnerabilidade refletem situações geográficas distintas; toda uma área ou população pode estar exposta a um mesmo risco, mas a vulnerabilidade varia dependendo das condições sócio-econômicas-culturais-políticasde uma dada sociedade explicitada na capacidade de absorver ou resistir aos impactos de um risco, ou sua capacidade de resiliência, isto é, capacidade de voltar ao estado de equilíbrio anterior à materialização do risco. Por exemplo, cidades localizadas em vales têm um maior risco de estarem sujeitas a deslizamentos e enchentes. Neste caso, a condição socioeconômica de cada morador, em morar em casas mais estruturadas e em áreas de menor risco, isto é, distantes das vertentes íngremes e não próximas aos cursos hídricos, acaba por definir seu grau de vulnerabilidade se um evento desse tipo for deflagrado.

As componentes relacionadas à capacidade de reação e à dificuldade de adaptação diante da materialização do risco (capacidade de resposta) estão associadas a uma "gama de implicações sociais, econômicas, tecnológicas, culturais, ambientais e políticas, que estão diretamente vinculadas à condição de pobreza de representativa parcela da sociedade moderna (MENDONÇA, 2004, 142). 
Em uma sociedade capitalista, guiada que é pelos princípios do mercado e da especulação e valorização do solo urbano, as áreas com menor risco acabam sendo as mais valorizadas pelo mercado imobiliário, o que as tornam mais caras e dificulta seu acesso para a maioria da população que, sem recursos, se sujeita a morar em áreas de maior risco e vulnerabilidade. Assim, observa-se que há uma estreita associação entre condições de pobreza urbana e áreas de maior exposição aos riscos naturais, por exemplo; esta associação se observa também, embora com menor vigor, quanto aos riscos tecnológicos e sociais.

Em resumo, pode-se dizer que, mesmo que risco e vulnerabilidade estejam sempre associados, e serem concebidos como risco e vulnerabilidade social, tecnológico e ambiental, o risco representa um perigo para um ambiente ou população envolvida de forma mais generalizada; já a vulnerabilidade é diferenciada segundo ambientes ou populações mais propensos ou suscetíveis a determinados riscos em decorrência de suas condições presentes. Assim, da mesma forma que é pertinente falar em vulnerabilidade socioambiental, também se pode falar em risco socioambiental.

Risco e vulnerabilidade são temas que oferecem importante contribuição para o entendimento da problemática socioambiental urbana. Este fato é evidenciado pelo aumento expressivo do número de trabalhos inscritos relacionados a este tema no GT - Problemática Socioambiental Urbana - no último evento do ENANPEGE - Encontro Nacional da ANPEGE. Esse aumento está ligado à própria condição dos centros urbanos no século XXI, que se tornaram, pela complexização do processo de urbanização brasileiro (SANTOS, 1993), ambientes cada vez mais propensos à riscos ambientais, tecnológicos e sociais, que causam consideráveis impactos aos ecossistemas e às populações humanas, posto que estas explicitam condições de vulnerabilidades diferenciadas no território nacional.

No XI ENANPEGE os trabalhos vinculados aesta subtemática (11 trabalhos) se concentraram em temas como: a vulnerabilidade ambiental e social (relacionada a eventos de grande precipitação pluviométrica, que decorrem em como impactos associados às enchentes e aos deslizamentos), ao risco tecnológico (como pool de combustíveis em áreas densamente ocupadas), ao saneamento, à saúde pública e à gestão municipal. Os trabalhos apresentados enfocaram diferentes escalas de análise no âmbito das cidades, indo desde o enfoque sobre bairros até municípios, ambientes litorâneos, bacias hidrográficas urbanas eáreas metropolitanas.

A maioria dos trabalhos enfocando os riscos e a vulnerabilidade socioambientais urbanos vinculadaao GT no ENANPEGE buscou destacar as distorções da relação sociedade e natureza como o principal desencadeador dos impactos associados. A terminologia empregada nestes trabalhos colocou em evidencia a abordagem socioambiental dos riscos 
e vulnerabilidades ambientais urbanos, explicitando cada vez mais a importância deste enforque na analise da produção e reprodução do espaço urbano brasileiro na atualidade.

\section{RECURSOS HÍDRICOS: VULNERABILIDADE SOCIOECONÔMICA E AMBIENTAL}

As discussões inerentes a escassez hídrica tem-se apresentado relevantes na análise do risco e da vulnerabilidade socioambiental, dado elevado nível de impacto sobre os recursos hídricos nas últimas décadas, o que reflete no aumento e agravamento da vulnerabilidade socioambiental, principalmente da população urbana. Assim, constituiu de tema apresentado e discutido no GT.

A disponibilidade dos recursos hídricos para o consumo não se encontra distribuída de forma homogênea, sendo bastante irregular no planeta, resultante da interação dos fatores climáticos e fisiográficos (regional e local). Em termos mundiais a agricultura utiliza $70 \%$ da água disponível, a indústria consome $20 \%$ e as residências 10\% (REBOUÇAS, 2003). Em países em desenvolvimento, a utilização da água pela agricultura pode atingir $80 \%$. Apesar da distribuição irregular dos recursos hídricos dividindo-se toda a água disponível pela população do planeta não haveria escassez. O volume de 80 litros/dia é o suficiente para garantir bons níveis de saúde e de higiene a uma pessoa (BANCO MUNDIAL, 1994).

Contudo, o problema de escassez hídrica tem-se agravado, atingindo proporções preocupantes em diversas localidades do planeta, principalmente nas últimas décadas do século XX e inicio do século XXI. Aproximadamente 460 milhões de pessoas são afetadas pela escassez de água e caso não haja alteração no estilo de vida da sociedade, um quarto da população mundial sofrerá este problema nas próximas décadas (HIRATA, 2003). Além do mais há que se considerar, em caráter urgente em função da gravidade da crise hídrica, $\mathrm{O}$ estabelecimento de políticas públicas que conduza a gestão dos recursos hídricos de forma a minimizar a vulnerabilidade socioambiental, principalmente da população reside em bairros pobres, na grande maioria áreas com grave deficiência de saneamento básico urbano.

O fato é que o déficit hídrico não está vinculado apenas à desigualdade espacial da distribuição da água ou mesmo devido aumento da demanda, observada nas últimas décadas. A crise da água, muito além de ser resultante da irregularidade na distribuição da água ou mesmo devido problemas oriundos da dinâmica natural, decorrentes principalmente da variabilidade climática, é resultante principalmente do mau gerenciamento dos recursos hídricos. A má gestão pública dos recursos hídricos agrava os problemas inerentes à sua distribuição, a partir dos desperdícios, contaminação e uso sem controle dos mananciais, tanto das águas superficiais quanto de subsuperfície. Estes fatores são os principais agravantes da crise hídrica na atualidade, com sérios desdobramentos principalmente 
para a população de menor poder aquisitivo, por representar parcela da população com maior nível de vulnerabilidade.

O desperdício da água aponta para um uso irresponsável desse precioso bem natural. Nas últimas décadas esse recurso, finito e não renovável, vem sendo ameaçado pelas ações indevidas da sociedade por falta de gerenciamento que permita o uso racional. A agricultura, por exemplo, se utiliza ainda de métodos ineficientes e obsoletos de irrigação o que permite o desperdício da água pela evaporação e pela percolação. Esta situação se agrava ainda mais nos países não desenvolvidos. Por outro lado, tradicionalmente os rios têm servido de receptores para os lançamentos do esgoto urbano, do lixo, e dos efluentes industriais, inviabilizando o consumo desta água. Esta realidade é bastante comum nos países em desenvolvimento, e aponta para um sério problema de saneamento básico urbano e gestão pública dos recursos hídricos.

Mesmo sendo considerado um dos países com maior disponibilidade de água do mundo, as metrópoles e cidades médias brasileiras enfrentam sérios problemas de abastecimento em função da crescente demanda. Esta demanda decorre do aumento acelerado da população nas últimas décadas, incremento da industrialização, maior demanda por água nos núcleos urbanos, aumento do volume de perdas de água decorrente de sistemas de rede de abastecimento obsoletos e baixos investimentos na manutenção e adequação das redes de abastecimento.O saneamento básico ineficiente ou inexistente, muitas vezes não acompanha o crescimento das cidades, e acaba por contribuir para agravar os problemas da crise hídrica no país, atingindo principalmente a população que reside nos grandes centros urbanos.

A má gestão dos recursos hídricos no Brasilé tão seria que problemas de abastecimentos ocorrem mesmo nas cidades situadas na Região Norte, região de maior vazão de água dos rios do país. A falta de saneamento básico e, a ineficiência da gestão pública em coibir lançamentos de produtos químicos nos cursos d'água, contamina os mananciais e os inviabilizam ao consumo humano. Nesta região, aproximadamente $47 \%$ da população não tem acesso à água tratada. Segundo Hurtado-Guerrero (2005), 95\% de determinados segmentos da população da região Amazônica são afetados por doenças infecciosas e parasitárias, decorrente das precárias condições de vida da população e por não terem acesso ao saneamento básico.

Por outro lado, a escassez quantitativa no semiárido é indicada como fator limitante ao desenvolvimento socioeconômico da região. Essa ideia de que a condição de semiárido da região nordeste é responsável pela baixa produtividade foi historicamente construída. 
O que ocorre, de fato, é que a região apresenta potencialidades naturais que permitiria o desenvolvimento sustentável capaz de melhorar a qualidade de vida da população. Para tanto, seria necessário apenas vontade política, de forma a fomentar a gestão dos recursos hídricos, e a adequação de técnicas modernas e compatíveis à realidade da região (REBOUÇAS, 1997).Contudo, trata-se deuma região nacionalmente conhecida pela escassez hídrica, agravada devido a política de gestão da água ocorrer de forma a privilegiar pequenos grupos, enquanto que a maior parte da população carece de acesso a água, expressando elevada vulnerabilidade socioambiental.

A crise hídrica no país se evidencia não somente nas grandes regiões metropolitanas e não estão relacionadas somente ao abastecimento, mas evidencia-se também sobre a produção de energia e sobre fatores econômicos. O principal fator atribuído a esta crise, segundo a gestão pública, está relacionada à variabilidade das chuvas sobre o país. Contudo, a variabilidade das chuvas no tempo e no espaço pouco pode explicar a falta de investimento, de saneamento básico e do uso racional da água. Nesse contexto, a região Centro-Oeste se apresenta como excelente exemplo quanto a sua importância no contexto nacional dos recursos hídricos, pois apresenta condição climática marcada por forte sazonalidade climática, dois períodos bem definidos, sendo um seco e o outro chuvoso.

Além desta característica climática, o Centro-Oeste brasileiro apresenta aspecto fisiográfico que lhe confere a característica de dispersor d'água para as grandes bacias hidrográficas brasileiras (SOWYER, 2009). A região representa importante área de recarga da água subterrânea e também oferece expressivas áreas de nascentes para rios que alimentam as bacias hidrográficas Amazônica; São Francisco e; Paraná. Contudo, apesar de representar $15 \%$ da disponibilidade hídrica no Brasil, o Centro-Oeste, cuja economia se assenta principalmente na produção agropecuária, nos aponta dois graves problemas que podem levar ao estresse hídrico da região com graves sequelas para as bacias hidrográficas que são beneficiadas pelos cursos d'água pertencentes a região.

O primeiro problema refere-se ao fato que a Região Centro-Oeste também é considerada o "celeiro do mundo" e como tal altamente produtiva, sendo para tanto utilizada tecnologia de ponta nos setores agropecuários, dentre estas a irrigação. Conforme já abordado neste texto, a partir da irrigação há desperdício por evaporação e a percolação da água, o que irá influenciar na vazão dos rios, principalmente durante o período de estiagem. Também é comum o represamento da água dos rios e córregos para atender a demanda da produção agropecuária, repercutindo na alteração da vazão, principalmente da vazão mínima, a jusante do curso d’água. 
O segundo problema que podemos inferir como sendo grave à crise hídrica no país refere-se às extensas áreas da região Centro-Oeste inseridas na economia agropecuária. $\mathrm{O}$ uso de forma intensiva e extensiva da região tende a provocar alteração do ciclo hidrológico. Esta alteração pode ocorrer a partir do momento quea infiltração das águas da chuva são inibidas devido a compactação das camadas superficiais do solo, mas também em função do comportamento hidromecânico dos solos tropicais não saturados, que inviabiliza, no inicio da estação chuvosa, a infiltração pluvial (LUIZ, 2012). Desta forma, há maior possibilidade de alteração da condição de infiltração de vastas áreas da região, repercutindo assim na variação da vazão mínima dos cursos d'água, na região Centro-Oeste, mas com repercussão para importantes bacias hidrográficas brasileiras.

A disponibilidade hídrica apresenta estreita relação com a oferta da precipitação e a baixa pluviometria influencia na oferta hídrica, podendo culminar no risco socioambiental em determinado momento para certas regiões brasileiras. Contudo, não se pode delegar ao clima os problemas inerentes à escassez hídrica, pois o padrão principal das chuvas, especialmente sobre as regiões tropicais, é a elevada variabilidade espacial e temporal (MENDONÇA e DANNI-OLIVEIRA, 2007). Portanto, esta dinâmica deve ser considerada na gestão dos recursos hídricos, pois o clima não responde pela falta de planejamento, de investimentos, de infraestrutura e da organização espacial condizente com as características físicas e ambientais assim como das demandas do local ou da região ocupada.

Assim, o país que é considerado com elevado potencial hídrico, 15\% do planeta, já no inicio do século XXI, é palco de grave crise decorrente do estresse hídrico, observada principalmente no setor energético. Em 2001, o déficit entre geração e consumo de energia elétrica culminou no maior racionamento de energia elétrica da história do Brasil. A redução do consumo durou de junho de 2001 a fevereiro de 2002. Os efeitos do racionamento não ficaram restritos somente ao consumo, influenciaram também na economia e na política sob os mais variados aspectos. O racionamento de energia elétrica no período 2001-2002 foi provocado por uma combinação de dois principais fatores: hidrologia e crescimento de mercado. Embora constatado diminuição da precipitação no período anterior ao racionamento, foi basicamente a falta de investimentos adequados à geração de energia elétrica no país que causou o racionamento.

Considerando que a disponibilidade de água é uma condição ao desenvolvimento de qualquer sociedade, a sua disponibilidade possui caráter estratégico, pois a partir da demanda pode haver conflitos. Dentre estes conflitos, cortar o acesso à água ou mesmo contamina-la é somente parte das estratégias estabelecidas no conflito (VALDÍVIA, 2006). Apesar da abundância hídrica do Brasil, foram registradas ocorrências de conflitos pelo 
uso da água. No ano de 2014, foram 127 ocorrências relacionadas a disputas por recursos hídricos; no ano de 2013 foram 101 ocorrências e; 79 disputas no ano de 2012. Das 127 ocorrências de disputas ocorridas no ano de 2014, 55 tinham relação com o uso e preservação da água; 49 estavam ligadas à instalação de barragens e açudes e; 23 notificações referem-se à apropriação particular de áreas em que a água era considerada um bem comum. Os Estados de Minas Gerais e da Bahia foram os estados que mais registraram notificações no ano de 2014, respectivamente com 26 casos, sendo que o número de famílias afetadas na Bahia foi maior (5.819) que em Minas Gerais (4.201). Dentre os conflitos por disputa de recursos hídricos no Brasil, destaca o ocorrido entre os Estados de São Paulo e Rio de Janeiro pelo uso da água do Rio Paraíba do Sul entre empresas urbanas de abastecimento de água (MARVEZZI, 2014).

No Brasil, Rocha et al. (2013) evidenciaram as diferenças regionais de disponibilidade hídrica, alertando para uma porcentagem considerável da população brasileira $(52,8 \%)$ com algum problema de disponibilidade hídrica, concentrados principalmente nas regiões Nordeste e Sudeste. Farias (2016) ao considerar o Índice de Desenvolvimento Humano municipal (IDH-M), obtido a partir das informações disponibilizadas pelo IBGE (2015), observou que as características de escassez de água são distintas nas regiões Nordeste e Sudeste. No Nordeste a escassez hídrica concentra-se em municípios pouco populosos do interior, junto ao Bioma Caatinga e baixos indicadores socioeconômicos (IDH-M baixo). Por outro lado, no Sudeste concentra-se em municípios bastante populosos e com boas condições socioeconômicas (IDH-M alto), evidenciando a falta de gestão publica no gerenciamento de políticas de uso e distribuição da água.

Nos últimos 2 anos (2014 e 2015) o Estado de São Paulo registrou uma das mais graves crises hídricas da história. Esta crise se acirrou devido a expressiva variação das chuvas que culminou em período marcado por baixa pluviometria justamente no momento quando deveria ocorrer a recarga hídrica no sistema. Este fato associado ao crescimento da demanda social e econômica da região considerada com os melhores índices econômicos e sociais do país culminou na grave crise na região metropolitana de São Paulo. Mesmo que a cidade de São Paulo apresente na sua malha urbana rios perenes (Tietê, o Pinheiros e o Tamanduateí), os mesmos não são potáveis, portanto inviável enquanto recurso, explicitando claramente a gravidade do desperdício a partir da contaminação dos mananciais.

Há que se considerar que as políticas de desenvolvimento econômico brasileiro, os avanços tecnológicos e as políticas públicas de incentivo, promoveram um modelo de sustentabilidade econômica apoiada na disponibilidade dos recursos do ambiente natural, principalmente na disponibilidade hidrometeorológica. Mas, mediante a grave crise que 
ocorreu no ano de 2014, é necessário gerenciar a disponibilidade hídrica para que haja sustentabilidade socioeconômica e ambiental.

Para tanto não se pode negligenciar a realidade socioambiental na busca de minimizar os riscos e a vulnerabilidade do estresse hídrico. Ao se considerar a dimensão ambiental e social na busca de solução para tais problemas, exige-se antes de tudo uma nova postura diante do planejamento, postura esta pautada na responsabilidade e no compromisso de atender a demanda hídrica considerando para tanto a dinâmica socioeconômica e ambiental.

Um conjunto de 12 contribuições científicas vinculadas à problemática da água recursos hídricos - nas cidades foi aprovado para apresentação no GT. Boa parte delas colocou em evidencia a preocupação com a questão do saneamento ambiental, suas insuficiências, debilidades e mesmo ausência em grande parte das cidades do país, fato que resulta na degradação das águas em todo o território nacional. Abordagens relacionadas à gestão das bacias hidrográficas urbanas, da fragilidade e vulnerabilidade em bacias hidrográficas, assim como a questão da relação entre a qualidade de vida e os mananciais de abastecimento também aparecem como temáticas de relevo nos trabalhos apresentados.

\section{RESÍDUOS SÓLIDOS URBANOS.}

O estágio mais atual da história humana é marcado por uma intensificação, em nível global (globalização), dos processos de produção e reprodução do espaço segundo a lógica do sistema de produção capitalista. Num contexto no qual predomina a apropriação privada dos meios e dos bens de produção, com uma explicita concentração da riqueza tanto na escala internacional quanto intra-nacional, generalizou-se a pobreza, inclusive nos países e um corolário de malefícios a ela direta e indiretamente associados.

No seu acirramento o sistema acabou por apostar numa maior produção de bens materiais e criou, concomitantemente, uma cultura que lhe deu suporte e força - a cultura do descarte. Entretanto, os diferentes Estados Nacionais não desenvolveram, na mesma medida e tempo, estratégias e ações que permitissem uma maior acessibilidade aos produtos, nem tampouco dotou as sociedades de mecanismos que reduzissem ou eliminassem os impactos derivados do acúmulo de excedentes materiais gerados no processo de produção e consumo modernos.

Constituiu-se, então, uma sociedade de forte base consumista que não gestou, no seu desenvolvimento, processos adequados de descarte, tratamento final e gestão responsável dos resíduos gerados no processo produtivo contemporâneo. Conforme Rodrigues (1998, p. 23) "um grande problema, da intensificação da produção/destrutiva,está no que se 
convencionou chamar de problemática ambiental, na criação de novas necessidades que não satisfazem necessidades humanas enriquecedoras, mas apenas correspondem a modos de vida da sociedade do descartável".

A natureza, em seus diferentes componentes, não consegue absorver e digerir todo o enorme volume cotidiano de resíduos gerados pelas diversas sociedades, e evidencia colapso ecossistêmico que se repercute, diretamente, na queda e no comprometimento da qualidade de vida humana.

No Brasil cerca de $60 \%$ dos 5.570 municípios não dispunham de aterros sanitários no ano de 2013. . Estes destinavam 41,7\%dos resíduos coletados para lixões e aterros controlados (ABRELPE, 2013). Assim, a maioria dos municípios mantém ainda processos de elevado consumo, geração de resíduos e não tratamento adequado dos mesmos. O lixo jogado a céu aberto, à esmo, os inúmeros lixões, o descarte clandestino, os comprometimentos com a saúde de populações, etc. levaram o governo federal a aprovar a Política Nacional de Resíduos Sólidos - PNRS, Lei Federal n 12.305/2010, regulamentada pelo $n^{\circ} 7.404 / 2010$, e exigir sua aplicação nos últimos anos. Todavia, há uma enorme distancia entre os princípios legais e a realidade concreta das populações, o que significa dizer que o problema dos resíduos urbanos mantém-se ainda altamente grave e distante de uma solução adequada.

Os problemas urbanos relacionados aos resíduos - especialmente os sólidos encontram claro eco nas perspectivas do GT - Problemática Socioambiental urbana - posto que revelam estreita relação entre práticas sociais-coletivas (geração, coleta e tratamento, ou apenas descarte!) e as bases naturais do território (solo, relevo, vegetação, clima, etc.). Os resíduos - sólidos, líquidos e gasosos - e seu tratamento, enquanto problemática socioambiental, explicita a imbricação direta de elementos de ordem social, política, econômica, cultural e tecnológica aos componentes naturais do sitio urbano.

$\mathrm{Na}$ realização do GT durante o evento do ENANPEGE em 2015, os enfoques evidenciados pelas contribuições científicas colocaram em destaque preocupações tanto com a gestão ambiental dos resíduos, quanto com as repercussões dos mesmos sobre os ecossistemas e as condições de vida a ele associados; cerca de 6 trabalhos foram apresentados envolvendo esta temática, sendo que a abordagem relativa aos catadores deu margem a um intenso debate acerca das condições atuais que envolve esta atividade em diferentes locais do país. 


\section{OUTRAS TEMÁTICAS.}

A problemática socioambiental urbana constitui um campo do conhecimento marcado porampla variedade de possibilidades subtemáticas de enfoque. Esta condição advém do fato de que o ambiente urbano, especialmente os problemas socioambientais a ele relacionados, coloca em evidencia uma miríade de problemas derivados da complexa relação estabelecida entre a sociedade e a natureza nas cidades, como colocado anteriormente.

Além das quatro temáticas supra-apresentadas, aquelas que aglutinaram o mais expressivo número de pesquisas em desenvolvimento, tanto em nível de mestrado quanto de doutorado, outros enfoques também tomaram importância no âmbito do GT. Assim é que a preocupação com a dinâmica de relevos tabuliformes submetidos à ocupação humana, as ilhas de calor urbano associadas àmobilidade urbana em sua nova configuração em função da Copa do Mundo de 2014, a expansão urbana, o papel do mercado imobiliário na gênese de problemas socioambientais urbanos variados, a segregação socioespacial e a questão da áreas verdes - fundos de vales urbanos, etc. constituíram temáticas abordadas nos mais diferentes trabalhos apresentados e debatidos no evento em Presidente Prudente em 2015.

\section{CONSIDERAÇÕES FINAIS.}

A geografia dedicou especial atenção aos problemas derivados da interação entre a sociedade e a natureza ao longo de toda a sua história. Outrora enfocados na perspectiva descritiva da geografia física, e sob forte influência do contexto conflituoso de meados do século XX, as abordagens mais gerais e também a geográfica passam a tratá-lo sob o enfoque ambiental; a partir do final do século o problema torna-se mais complexo e, por evidenciar a preponderância social de sua gênese e repercussões, reveste-se de um enfoque socioambiental. Nas duas últimas décadas esta perspectiva toma maior importância e revela a estreita imbricação entre processos sociais (geografia humana) e processos naturais (geografia física) como dimensões necessárias na análise e compreensão dos referidos problemas.

Um conjunto variado de entidades voltadas à promoção e defesa da pesquisa e pósgraduação foi fundado no Brasil no processo de redemocratização que se desenvolveu a partir dos anos 1980. A ANPEGE nasceu neste contexto e com esta finalidade, atrelada diretamente ao campo do conhecimento geográfico; seu desenvolvimento foi marcado pela construção democrática do conhecimento, para o que se estimulou o debate como condição fundamental para a produção científica da Geografia em nível de pós-graduação. Uma das atividades que deu vida à esta iniciativa foi a criação dos GTs - Grupos de Trabalho - 
realizados durante os encontros bi-anuais da entidade; o GT - Problemática Socioambiental Urbana foi criado neste contexto, e aglutina pesquisadores, professores e estudantes que se envolvem com a produção do conhecimento relacionada ao ambiente urbano.

Vários são os subtemas ligados à abordagem da problemática socioambiental urbana, estando eles presentes na produção da pesquisa, de teses e dissertações de quase todos os programas de pós-graduação em geografia no Brasil. No XI ENANPEGE realizado em Presidente Prudente, em 2015, três subtemáticas tomaram destaque, sendo elas relacionadas aos riscos e vulnerabilidades socioambientais, aos resíduos sólidos urbanos e à questão hídrica nas cidades; entretanto, várias outras subtemáticas também apareceram de forma menos evidente - Outros.

A quantidade de trabalhos - contribuições científicas - vinculadas à temática do GT vem crescendo desde a primeira realização do mesmo (2009, em Curitiba). A troca de experiências e conhecimentos a partir das apresentações dos trabalhos, e dos debates que a elas se seguem, tem possibilitado consideráveis avanços nas abordagens teóricas e metodológicas da temática, aspecto que aponta positivamente para continuidade e perenidade do GT.

Mesmo considerando-se que a urbanização foi o principal processo de dinamização das cidades no século XX, e que a cidade é fato predominante no século XXI (CHOAY, 2003), entende-se o as áreas urbanas brasileiras reservam dinâmicas inovadoras e surpreendentes no seu porvir. Entende-se também que a solução de grande parte dos problemas atinentes à qualidade vida nas cidades do país está bastante longe de ser alcançada, ainda que esforços importantes tenham sido observados neste sentido na última década. Assim, é de se imaginar que os problemas socioambientais urbanas estarão, por muito tempo, presentes na agenda de interesses da abordagem geográfica; ao se identificar a sua recente construção como um tema de interesse da geografia, estima-se seu grande potencial para o desenvolvimento de promissores estudos no campo desta ciência.

\section{REFERÊNCIAS.}

1. ASSOCIAÇÃO BRASILEIRA DE EMPRESAS DE LIMPEZA PÚBLICA E RESIDUOS ESPECIAIS - ABRELPE. Panorama dos resíduos sólidos no Brasil 2013. São Paulo: ABRELPE, 2013.

2. ABRAMOVAY, M. et al. Juventude, violência e vulnerabilidade social na América Latina: desafios parapolíticas públicas. Brasília: UNESCO, 2002. 
3. BANCO MUNDIAL. La ordenación de lós recursos hídricos. 1994.

4. .BECK, U. Risk society: towards a new modernity. Londres: SagePublications, 1992.

5. .CHOAY, F. O urbanismo - Utopias e realidades : Uma antologia. São Paulo: Perspectiva, 2003.

6. CONFERENCIA DAS NAÇÕES UNIDAS PARA O MEIO AMBIENTE E O DESENVOLVIMENTO. Agenda 21 -capítulo 18.Protection of the quality and supply of the quality and supply of freshwater resources: Application of integrated approaches to the development, management and use of water resources, 1992.

7. .DESCHAMPS, M. V. Vulnerabilidade socioambiental na Região Metropolitana de Curitiba. 2004. Tese(Doutorado em Meio Ambiente e Desenvolvimento) - Universidade Federal do Paraná, Curitiba, 2004.Disponível em:<http://www.ipardes.gov.br/biblioteca/docs/tese_ marley_deschamps.pdf $>>$. Acesso em: janeiro, 2016.

8. .ESTEVES, C. J. de O. Risco e vulnerabilidade socioambiental: aspectos conceituais. Caderno IPARDES, Curitiba: IPARDES, v.1, n.2, p. 62-79, 2011.

9. .FARIAS, S. E. M. Estimativas satelitárias de precipitação sobre o bioma cerrado brasileiro: possibilidades e perspectivas. (Tese de Doutorado). Universidade Federal de Goiás. Goiânia. 2016.

10. .FOCAULT, M. A Arqueologia do Saber. 8 ed. Rio de Janeiro: Forense Universitária, 2013.254 p.

11. .HIRATA, R. Recursos Hídricos. In: TEIXEIRA, W.; TOLEDO, M.C.M.; FAIRCHILD, T.R.; TAIOLI, F. (Orgs.). Decifrando a Terra. São Paulo: Oficina de Textos, 2003. p. 421-444.

12. .HURTADO-GUERRERO, A.F.; ALENCAR, F.HL; HURTADO-GUERRERO, J.C. Ocorrências de enteroparasitos na população geronte de Nova Olinda do Norte: Amazonas, Brasil. Acta Amazônica, 2005; 35(4): 487-490.

13. .LUIZ, G.C. A influência da relação solo-atmosfera no comportamento hidromecânico de solos tropicais não saturados: estudo de caso - município de Goiânia. (Tese de Doutorado). Universidade de Brasília. Brasília, maio. 2012.

14. .MARANDOLA JR., E.; HOGAN, D. J. Natural hazards: o estudo geográfico dos riscos e perigos. Ambiente\& Sociedade, Campinas: UNICAMP/NEPAM, v.7, n.2, p.95-109, jul./dez, 2004. Disponível em: <http://www.scielo.br/pdf/asoc/v7n2/24689.pdf>. Acesso em: janeiro, 2016.

15. .MARANDOLA JR., E.; HOGAN, D. J. As dimensões da vulnerabilidade. São Paulo em Perspectiva,São Paulo: Fundação SEADE, v.20, n.1, p.33-43, jan./mar., 2006.Disponível em: <http://www1.eesc.usp.br/ppgsea/files/v20n01_03.pdf>. Acesso em: janeiro, 2016.

16. .MARVEZZI, R. Conflitos por água nos últimos 10 anos. In: CANUTO, A.; LUZ, C.R.S.; COSTA, E. R. (Orgs.). Conflitos no campo. Goiânia: CPT Nacional, p. 98-106. 2014.

17. .MENDONÇA, F. Geografia Socioambiental. Revista terra livre, São Paulo, n. ${ }^{\circ}$ 16, p. 139$158,2001$.

18. .MENDONÇA, F. (Org.) Impactos socioambientais urbanos. Curitiba: Editora da UFPR, 2004.

19. .MENDONÇA, F. Riscos, vulnerabilidade e abordagem socioambiental urbana: uma reflexão a partir da RMC e de Curitiba. Desenvolvimento e Meio Ambiente, Curitiba, Ed. da UFPR, n.10, p.139-148,jul./dez., 2004. 
20. .MENDONÇA, F. e DANNI-OLIVEIRA, I. M. Climatologia: Noções básicas e climas do Brasil. São Paulo: Oficina de Textos, 2007.

21. .MONTEIRO, C. A. F. Teoria e clima urbano. São Paulo: USP, 1976 (Tese de Livre-docência).

22. .MOSCOVICI, S. Natureza - Para pensar a ecologia. Rio de Janeiro: MAUAD X - Instituto GAIA, 2007. (Coleção EICOS). 254p.

23. .PNUD - PROGRAMA DE LAS NACIONES UNIDAS PARA EL DESARROLLO. UNOPS - OFICINA DE SERVIVIOS PARA PROYETOS DE LAS NACIONES UNIDAS. PROYETO REGIONAL DE CAPACITACION EM GESTION AMBIENTAL URBANA. Guia metodológica de capacitacion em gestion ambiental urbana para universidades de América Latina y el Caribe. Santiago de los Caballeros: CEUR/PUCMM, noviembre de 1996.

24. .REBOUÇAS, A. C. Água na região Nordeste: desperdício e escassez. Estudos Avançados (online). 1997, vol.11, n.29, p.127-154. Disponível em: Http::/dx.doi.org/10.1590/S010340141997000100007.

25. .REBOUÇAS, A. C. Água no Brasil: abundância, desperdício e escassez. Bahia análise \& dados. Salvador, Bahia. v. 13, n. Especial, p. 341-345. 2003.

26. .RODRIGUES, A. M. Produção e consumo do e no espaço - Problemática ambiental urbana. São Paulo: Hucitec, 1998.

27. .ROCHA, G. C.; ROMÁN, R.M.S.; FOLEGATTI, M.V.; LINO, J.S. Aspectos físicos e sociais da geografia da disponibilidade hídrica municipal no Brasil. Irriga. Botucatu, São Paulo, v. 18, n. 3, p. 402-414, jul./set. 2013.

28. .SANTOS, M. A urbanização brasileira. São Paulo: Hucitec, 1993.

29. SOWYER, D. Fluxos de carbono na Amazônia e no Cerrado. Sociedade e Estado. Brasília, v. 24, n.1, p. 149-171. 2009.

30. .VALDIVIA, R. Água e pobreza. VientoSur.n. 87, p.27-38. jul. 2006.

31. VEIGA, J. E. A Emergência Socioambiental. São Paulo: Ed. Senac, 2007. 160p.

32. .VEYRET, Y. Os riscos: o homem como agressor e vítima do meio ambiente. São Paulo: Contexto, 2007.

Artigo recebido em 28 de junho de 2016.

Artigo aceito em 28 de julho de 2016. 